\title{
Effectiveness of Utero-Vaginal Packing in Management of Postpartum Hemorrhage
}

\author{
Lubna Javed, ${ }^{1}$ Shamila Ijaz Munir, ${ }^{2}$ Amna Zia Eusaph ${ }^{3}$
}

\begin{abstract}
A major cause of maternal mortality and morbidity in developing world is post-partum hemorrhage (PPH). Different management options have been in use including use of oxytocins, prostaglandins, surgical exploration of genital tract, ligation or angiographic embolization of uterine/internal iliac arteries and hysterectomy. A simple and effective measure is to control bleeding with utero-vaginal packing which is easy and quick to perform and saves the patient need of major surgical procedures.
\end{abstract}

Objective: To determine effectiveness of utero-vaginal packing in control of post-partum hemorrhage, its safety and complications associated with it.

Place and Duration of Study: This study was carried out in Gynae unit 1 of Lady Willingdon Hospital Lahore from January 2014 - June 2015.

Patients and Methods: It was a prospective interventional study. The patients presenting with postpartum hemorrhage after vaginal or abdominal delivery who

\footnotetext{
${ }^{1}$ Assistant Professor, Department of Obstetrics \& Gynaecology, SIMS/Services Hospital, Lahore.

${ }^{2}$ Assistant Professor, Department of Obstetrics \& Gynaecology, KEMU/ Lady Willingdon Hospital, Lahore.

${ }^{3}$ Associate Professor, Department of Obstetrics \& Gynaecology, KEMU/Lady Willingdon Hospital, Lahore.
}

Date of Submission: 22-07-2016

Date of Acceptance for publication: 03-01-2017

Conflict of Interest: None

Funding Source: None

\section{Contribution}

All Authors have contributed in Study Design, Data Collection, Data Analysis, Data Interpretation, Manuscript Writing and Approval. did not respond to medical management were included in the study. Patients who had PPH due to genital tract trauma were excluded from this study. Frequencies and proportions of complications were calculated along with rate of successful cessation of bleeding. Data was analyzed by SPSS version 11.

Results: 99 patients who presented with PPH were included in study. $49.5 \%$ were between age of $31-40$ years, $38.4 \%$ were between $21-30$ years. $8.1 \%$ of patients were P1-2, 52.5\% were P3-5 and $39.4 \%$ were P6 and above. $76.7 \%$ had hemorrhage after vaginal delivery and $23.3 \%$ after lower segment caesarean section. Uterineatony was the most common cause of postpartum hemorrhage, seen in $78.78 \%$ of cases, $9.09 \%$ had placenta previa, $8.08 \%$ presented with abruption placenta and $4.04 \%$ had coagulopathy. Regarding complications 7 women had to undergo hysterectomy, fever occurred in $14.14 \%, 8.08 \%$ had wound infection and 2 patients died of Disseminated Intravascular Coagulation (DIC). Procedure was successful in $90.9 \%$ of cases.

Conclusion: Utero-vaginal packing effectively controls postpartum hemorrhage with fewer complications and its role in emergency obstetric scan not be denied.

Key Words: Postpartum hemorrhage, utero-vaginal packing, efficacy, maternal mortality.

\section{Introduction}

About 5,290,000 women die annually worldwide due to a cause related to child birth, $90 \%$ of those deaths occur in the developing world. Pakistan has one of the highest maternal mortality rates which is $260 / 100,000$ live births. ${ }^{1} \mathrm{PPH}$ is a major killer which complicates about $5 \%$ of deliveries and is responsible for 150,000 deaths annually. Multiparous women with advanced maternal age, ones who are obese or have over-dis- 
tended uterus or have induced or prolonged labour or with placenta previa are at risk of PPH. The leading cause is uterine atony in $>90 \%$ of cases whereas genital tract trauma, Retained Product of Conception (RPOCS) and coagulopathy are other factors. PPH is an obstetric emergency which requires prompt diagnosis and effective actions to prevent maternal mortality. $^{2}$

Utero-vaginal packing for PPH has been in use for decades. After 1960s because of fear of infection and concealed hemorrhage its use subsequently declined. However isolated reports of its successful use have been published. ${ }^{3}$ PPH has been major cause of maternal mortality and requires immediate hemodynamic resuscitation measures and steps to control hemorrhage which include uterine massage and uterotonics. If bleeding is still not controlled, exploration in operation theatre, uterine and ovarian artery ligation, B Lynch suture, internal iliac artery ligation and hysterictomy may be required. ${ }^{4}$ In recent decades there has been a search for conservative method to avoid operative procedures in patients unresponsive to uterotonics. Utero-vaginal packing by causing mechanical compression of uterine vascular sinuses is a quick, effective and cheap method of securing haemostasis in a large number of cases. ${ }^{5,6}$ So if medical management fails, uterine packing is a simple and effective method which can avoid other complicated surgical procedures and help save life of mothers. ${ }^{7}$

The most common indication for use of uterine packing is uterine atony. Bleeding from placental site in placenta previa or placenta accreta and some cases of coagulopathy are other indications. In certain cases where patients are being prepared for a surgical procedure, utero-vaginal packing can be used to stabilize the patient. In some of these patients uterine packing controls bleeding successfully, thereby further surgery may not be required. ${ }^{6,7}$

Uterine packing can be easily learnt as that it is very simple and quick to perform and no special technique or equipment is needed. It requires tight uniform packing of whole uterine cavity continued vaginally to the introitus so that a tamponade effect is maintained on the uterine sinuses to prevent hemorrhage. If hemorrhage is not controlled with a tightly placed packing, it is not recommended to repack the uterus. One should resort to other options to control hemorrhage. ${ }^{8}$

There are some other methods of uterine tamponade which have been used over the years. The Sengstaken-Blakemore tube is one of these. It is equipped with a drainage channel to prevent concealed hemorr- hage. However, it is not easily available. ${ }^{9}$ Tamponade with a condom inflated with $250-500 \mathrm{~mL}$ of saline has been used and is found to be helpful in controlling PPH in cases of uterine atony and placenta previa. ${ }^{10}$ The rationale of this study is that the procedure is simple and quick to perform. It can be easily learnt and no special equipment is required.

\section{Patients and Methods}

It was a prospective interventional study conducted in GynaeUnit-1 of LWH from Jan 2014 to June 2015. Permission was taken from ethical committee of Hospital. The 99 patients were included in study who presented with primary PPH due to uterine atony along with some cases of placenta previa, abruption and coagulopathies. Cases with genital tract trauma were excluded. Patient was placed in lithotomy position and uterine packing was started from fundus with $8-$ 10 meter gauze with the help of sponge holding forceps up to the cervix. Additional packing of vagina was also done to give a firm compression. Asepsis was maintained. Patient was kept in high dependency area for $24-48$ hours. Vitals were monitored strictly. Blood and blood products were transfused as per individual requirement. Packing was removed after 24 48 hours. Antibiotics were given intravenously for 5 7 days. Syntocinon infusion was continued till 12 hours after removal of pack. Procedure was considered effective if bleeding stopped after packing and patient was stable and considered safe if there were minimal or no complications. Patients were followed upto six weeks in the outpatient clinic. All information was collected on a pre-designed proforma. Data was analyzed by SPSS version 11. Frequency and percentages were calculated for qualitative variables like, gravidity, parity, cause of uterine bleeding, efficacy and complications.

\section{Results}

99 patients presented with PPH during study period. Among them $49.5 \%$ were between 31 - 40 years, $38.4 \%$ were between $21-30 y e a r s, 8.1 \%$ of patients were P1-2, 52.5\% were P3-5 and $39.4 \%$ were P6 and above. $76.7 \%$ had hemorrhage after vaginal delivery and $23.3 \%$ after lower segment cesarean section. Regarding causes uterine atony unresponsive to oxytocin was the most common cause seen in $78.78 \%$ of cases, $9.09 \%$ had placenta previa, $8.08 \%$ patients had abruption placenta and $4.04 \%$ had coagulopathy. 
There were few complications, 7 patients had to undergo hysterectomy because of uncontrolled hemorrhage, fever developed in $14.14 \%, 8.08 \%$ had wound infection, and $2(2.02 \%)$ patients died due to DIC. Procedure was successful in $90.9 \%$ of cases.

Table 1:

\begin{tabular}{|c|c|c|}
\hline Variable (n=99) & Frequency & Percentage \\
\hline \multicolumn{3}{|l|}{ Age } \\
\hline $21-30$ & 38 & 38.4 \\
\hline $31-40$ & 49 & 49.5 \\
\hline$>41$ & 12 & 12.1 \\
\hline \multicolumn{3}{|l|}{ Parity } \\
\hline $\mathrm{P} 1-2$ & 8 & 8.1 \\
\hline P3-5 & 52 & 52.5 \\
\hline P6 and above & 39 & 39.4 \\
\hline \multicolumn{3}{|l|}{ Mode of Delivery } \\
\hline Vaginal & 76 & 76.76 \\
\hline Cesarean & 23 & 23.3 \\
\hline \multicolumn{3}{|l|}{ Indication } \\
\hline Uterine atony & 78 & 78.78 \\
\hline Coagulopathy & 4 & 4.04 \\
\hline Placenta previa & 9 & 9.09 \\
\hline Abruption placenta & 8 & 8.08 \\
\hline \multicolumn{3}{|l|}{ Complications $(n=31)$} \\
\hline Hysterectomy & 7 & 7.07 \\
\hline Fever $>100 \mathrm{~F}$ & 14 & 14.14 \\
\hline Wound infection & 8 & 8.08 \\
\hline Mortality & 2 & 2.02 \\
\hline
\end{tabular}

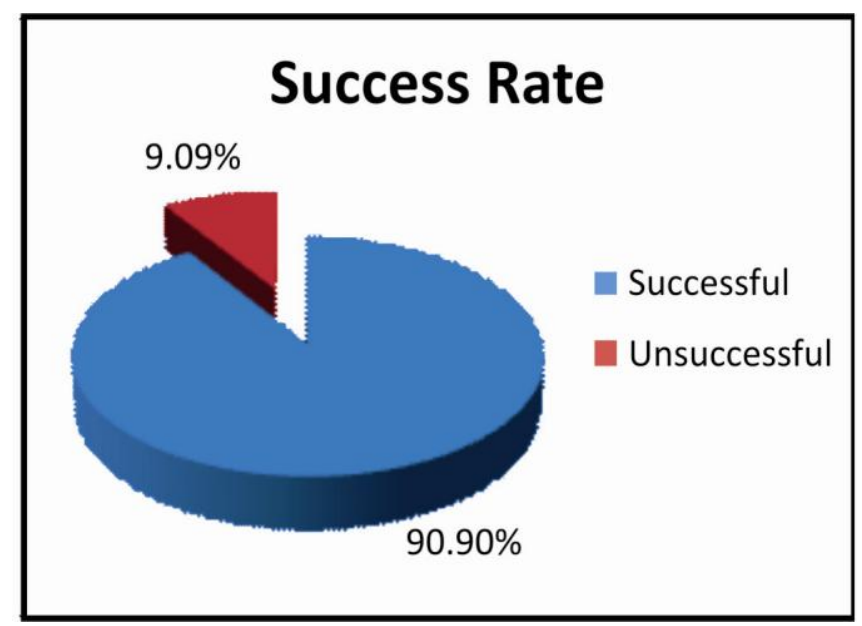

Fig. 1:

\section{Discussion}

PPH is a major killer of mothers which requires immediate resuscitation. After excluding genital tract lacerations and retained placental tissue, efforts are directed towards causing the uterus to contract by bimanual compression and oxytocin. If these are not successful, one has to resort to surgical techniques like ligation of uterine, ovarian or internal iliac arteries and hysterectomy in certain cases. Before resorting to surgical procedures an alternative option is uterovaginal packing. Easy and quick to perform, it controls bleeding by tamponade effect and surgery is not required in most of cases. ${ }^{6,10}$

Management of PPH requires team work, maintaining hemodynamic stability of woman while simultaneously identifying and treating the cause of blood loss. The key factors to save the life of the mother are active management of third stage of labor and prevention and treatment of postpartum hemorrhage. ${ }^{11}$

Witch. Et al, have recommended uterine packing as a pre-surgical procedure after exclusion of lacerations of lower genital tract, uterine rupture and retained placental tissue. ${ }^{12}$ Our study also included cases of non-traumatic uterine hemorrhage and success rate of uterine packing was $90.09 \%$. In a study by Ali et al 42 patients in whom utero-vaginal packing was done, 36 $(86 \%)$ responded to the procedure; failure to achieve hemostasis occurred in $6(14 \%)$ cases. Cesarean hysterectomy was done in $3(7 \%)$ patients, while $1(2 \%)$ patient died due to multiple organ failure. ${ }^{13}$

A study conducted by Roman and Rebarber et al, showed that success of uterine packing was clinically evident after procedure was completed. In some cases 
packing material became heavily stained with seroanguinous fluid. There was minimal fever which settled with medicines and of no clinical significance. ${ }^{14}$ Comparing this with our study as regards post insertion morbidity, three patients developed pyrexia and one patient developed episiotomy wound infection. Concealed hemorrhage was not seen in any of our patients, however there was some soakage of the packing. Most of these complications settled with treatment.

In a study conducted by Mobusher I. et al, success rate of uterine packing was $87.5 \%$ while 4 patients out of 40 underwent hysterectomy. ${ }^{15}$ In our study 7 out of 99 patients had to undergo hysterectomy because of uncontrolled hemorrhage.

Around 1960s uterine packing with gauze was out of favor because it was thought to conceal hemorrhage and cause infection. But these concerns were not confirmed with further studies and this technique re-emerged in 1980s and 1990s. ${ }^{16} 85 \%$ of patients had successful control of PPH in a study conducted by Haq G and Tayyab S. 2 patients had to undergo hysterectomy and there was one mortality. ${ }^{17}$

Developing countries have high incidence of PPH mainly due to poor antenatal attendance and lack of screening of high risk patients. $70 \%$ women do not receive skilled intra-partum care and are rushed to hospital with complications in a moribund state only. ${ }^{18}$ In some of these cases emergency obstetric procedures even hysterectomy has to be done to save her life which is associated with severe blood loss, intra-operative complications and significant post-operative mortality and morbidity. ${ }^{19}$ In many of these patients, simple procedure of uterine packing can save woman of major surgical procedure and burden on resources of hospital.

\section{Conclusion}

Utero-vaginal packing is a useful technique for control of postpartum hemorrhage. It is a simple, fast and cost effective procedure which can be easily taught to trainee residents and even midwives and helps reduce maternal morbidity and mortality.

\section{References}

1. UNICEF: Maternal mortality. Available at: http://www.unicef.org/infobycountry/pakistan_pakistan _statistics.html. Last accessed: $25^{\text {th }}$ March 2015.
2. Department of Health, Scottish Executive Health Department, and Department of Health, Social Services and Public Safety, Northern Ireland. Why Mothers Die. Sixth report on confidential enquiries into maternal deaths in the United Kingdom, 2000-2002. London: RCOG Press; 2004.

3. F Ghezzi AA, Cromi AS, Uccella AL, Raio BP, Bolis $\mathrm{AD}$, Surbekb. The Hayman technique: a simple method to treat postpartum haemorrhage RCOG. BJOG. 2007; 14 (3): 362-365.

4. Nizam K, Haider G. Hemorrhage Role of Uterovaginal Packing in Postpartum Hemorrhage. JLUMHS. 2010; 09 (1): 27-29.

5. Bagga R, Jain V, Ka1ra J, Chopra S. Uterovaginal packing with rolled gauze in PPH. Med Gen. 2004; 6 (1): 50.

6. Li Yt, Yin CS, Chen FM, Chao TC. A useful technique for the control of severe Caesarian haemorrhage: Report of three cases. Chang Gung Med J. 2002; 25 (8): 548-52.

7. Shevell T, Malone FD. Management of obstetric haemorrhage. Semin Perinatol 2003; 27 (1): 86-104.

8. Hsu S, Rodgers B, Lele A, Yeh J. Use of packing in obstetric hemorrhage of uterine origin. J Reprod Med. 2003; 48: 69-71.

9. Seror J, Allouche C, Elhaik S. Use of Sengstaken Blackmore tube in massive postpartum hemorrhage. A series of 17 cases. Acta Obstet Gynecol Scand. 2005; 84 (7): 660-4.

10. Bagga R, Jain V, Chopra S, Karla J, Gopalan S. Uterovaginal Packing With Rolled Gauze in Postpartum Hemorrhage. Med Gen Med. 2004; 6 (1): 50.

11. Leduc D, Senikas V, Lalonde AB, Ballerman C, Biringer A, Delaney M, et al. Clinical Practice Obstetrics Committee; Society of Obstetricians and Gynaecologists of Canada. J Obstet Gynaecol Can. 2009; 31 (10): 980-93.

12. Wittich AC, Salminen ER, Hardin EL, Desantis RA. Uterine Packing in Combined Management of Obstetric Hemorrhage. Mill Med. 1996; 161: 180-2.

13. Ali T, Ghazi A, Siddiq NM. Uterovaginal packing in massive postpartum hemorrhage - a reappraisal. Pak J Surg. 2008; 24 (1): 57-9.

14. Roman AS, Rebarber A. Seven ways to control postpartum haemorrhage Contemporary OB/Gyn Newsline. 2003; 3: 1-14.

15. Iram M. Role of uterine packing in control of PPH. PJMHS. 2011; 5 (3): 442-444.

16. Mousa HA, Alfirevic Z. Treatment for primary postpartum haemorrhage. Cochrane Database of Systematic Reviews. 2007; 24 (1). CD003249.

DOI: $10.1002 / 14651858$

17. Haq G, Tayyab S. Control of postpartum and post abortal haemorrhage with uterine packing. JPMA. 2005; 55 (9): 369-371. 
18. MunirI S, Sadiq A, Ishtiaq S. Frequency of causes of primary postpartum haemorrhage in a tertiary care hospital. Annals. 2015; 21 (1): 33-37.
19. Korejo R, Nasir A, Yasmin H, Bhutta S. Emergency obstetric hysterectomy. JPMA. 2012; 62 (12): 13221325. 